\title{
Concept and Economic Evaluation of Prescriptive Maintenance Strategies for an Automated Condition Monitoring System
}

\author{
Robert Meissner ${ }^{1}$, Hendrik Meyer $^{2}$, and Kai Wicke ${ }^{3}$ \\ 1,2,3 German Aerospace Center (DLR), Hamburg, 21129, Germany \\ robert.meissner@dlr.de \\ hendrik.meyer@dlr.de \\ kai.wicke@dlr.de
}

\begin{abstract}
In order to reduce operating costs and increase the operational stability, the aviation industry is continuously introducing digital technologies to automate the state detection of their assets and derive maintenance decisions. Thus, many industry efforts and research activities have focused on an early state fault detection and the prediction of system failures. Since research has mainly been limited to the calculation of remaining useful lifetimes (RUL) and has neglected the impact on surrounding processes, changes on the objectives of the involved stakeholders, resulting from these technologies, have hardly been addressed in existing work. However, to comprehensibly evaluate the potential of a fault diagnosis and failure prognosis system, including its effects on adjacent maintenance processes, the condition monitoring system's maturity level needs to be taken into account, expressed for example through the technology's automation degree or the prognostic horizon $(\mathrm{PH})$ for reliable failure projections. In this paper, we present key features of an automatic condition monitoring architecture for the example of a Tire Pressure Indication System (TPIS). Furthermore, we develop a prescriptive maintenance strategy by modeling the involved stakeholders of aircraft and line maintenance operations with their functional dependencies. Subsequently, we estimate the expected implications for a small aircraft fleet with the introduction of such a monitoring system with various levels of technological maturity. Additionally, we calculate the maintenance cost savings potential for different measurement strategies and compare these results to the current state-of-the-art maintenance approach. To estimate the effects of implementing an automated condition monitoring system, we use a discrete-event, agentbased simulation setup with an exemplary flight schedule and a simulated time span of 30 calendar days. The obtained results allow a comprehensive estimation of the maintenance
\end{abstract}

\footnotetext{
Robert Meissner et al. This is an open-access article distributed under the terms of the Creative Commons Attribution 3.0 United States License, which permits unrestricted use, distribution, and reproduction in any medium, provided the original author and source are credited.

https://doi.org/10.36001/IJPHM.2021.v12i3.2911
}

related implications on airline operation and provide key aspects in the development of an airline's prescriptive maintenance strategy.

\section{INTRODUCTION}

In recent years, the aviation industry has spent significant research efforts on topics of early stage fault detection and remaining useful life (RUL) prognosis, to effectively monitor and optimize their assets utilization, e.g. in Chiachío, Chiachío, Saxena, Rus, and Goebel (2013) and Loutas, Eleftheroglou, and Zarouchas (2017) for structural health monitoring (SHM) approaches or in Ritter et al. (2018) and Poole (2015) for condition monitoring techniques of aircraft components and systems. The developed technologies promise to effectively improve the operational stability and dispatch reliability by preventing the loss of airworthiness or ensuring the completion of planned missions. However, despite these research efforts for monitoring the system condition, the challenge from operators remains in the uncertainty of maintenance needs. Thus, to exploit the full potential of monitoring technologies, a decision tool for condition-based fleet maintenance planning has to be developed. (Freeman, 2019)

Although evaluating new monitoring technologies in maintenance towards their operational impact has been focus of multiple papers, these efforts usually do not consider changes of the overall impact on airline operations with changing technology maturity levels. As of this paper, we define the technological maturity as the capability of a condition monitoring technology to reliably detect system degradation and project maintenance requirements. To establish a feedback loop between technology development and operational assessment and to contribute to an optimized system behavior, the implementation of an automated state detection has to consider the following aspects (Vachtsevanos \& Goebel, 2015):

- Simultaneous consideration of aspects of maintenance, operations, and logistics,

- Definition of minimum performance criteria for devel- 
oped prognostics and health management technologies, and

- Derivation of optimized maintenance decisions based on the continuous condition monitoring and prognosis.

For this paper, based on these requirements, we will develop a prescriptive maintenance strategy for an automated tire pressure management system. As Nemeth, Ansari, Sihn, Haslhofer, and Schindler (2018) define, a prescriptive maintenance strategy utilizes failure projections to minimize the operational implications of necessary maintenance tasks. It will, therefore, be an evolution of predictive maintenance strategies, which purely forecast upcoming system failures based on observations in the past. We will further conduct an evaluation for different technology maturity levels for an automated condition monitoring system for the example of an A320 Tire Pressure Indication System (TPIS). As of this paper, the focus of this assessment will be beyond the aircraft itself and also consider adjacent maintenance processes and required maintenance resources for task completions. The different maturity levels of the condition monitoring technology will be modeled by changes in the measurement strategy, the degree of task automation, and capabilities for different prognostic horizons $(\mathrm{PH})$. Additionally, we will analyze the effect of different levels of maintenance operations, i.e. the daily time span at the designated maintenance base where manual labor tasks can be executed. Starting from a 24 hours maintenance operations window, we will steadily decrease the available slots at the maintenance base by reducing the available ground resources in order to analyze subsequent changes on the average waiting times for service and the average fleet utilization.

This paper will be structured as follows: In section 2, we will present an overview of current aircraft maintenance, a literature review of related state-of-the-art research, and a theoretical layout for an automated condition monitoring infrastructure to allow a prescriptive maintenance planning. The use-case scenario including the simulation setup and our developed method for an prescriptive maintenance planning will be described in section 3 . We will finally calculate the expected implications towards airline operation for the different defined scenarios in section 5 .

\section{SYSTEM DESCRIPTION}

In order to illustrate the necessity for this paper, the current maintenance approach and its regulatory requirements, the state-of-the-art in research including the identified research gaps as well as a methodology for identifying maintenance tasks with high savings potentials by automation are explained.

\subsection{Basic Aircraft Maintenance}

The basic principle of aircraft maintenance follows the approach of a reliability-centered maintenance (RCM). The goal here is to maximize the operational safety and reliability of any physical asset while minimizing the associated costs (Gerdes, Scholz, \& Galar, 2016). In general, it can be subdivided into two main categories: preventive and corrective maintenance. The category of preventive maintenance itself is divided into the area of condition-based maintenance, with maintenance decision made on the monitored condition of the respective system, and scheduled maintenance, where tasks will be executed according to a predetermined time-interval, either in calendar days or on a flight hours (FH) or flight cycles (FC) basis. (Deutsches Intstitut für Normung e.V., 2010)

As a particular form of RCM, the idea of the maintenance steering group (MSG) analysis has been developed for the area of airline operations. Currently, the main approach for developing the initial maintenance schedule with the required task intervals is the $3^{\text {rd }}$ generation of the MSG analysis methodology. Unlike its predecessors, the main idea here is to conduct scheduled, interval-based functionality checks instead of hard-time system replacements. (Kinnison, 2004)

By outlining the general process for determining the scheduled maintenance requirements according to the system criticality, the MSG-3 analysis enables the development of an maintenance review board report (MRBR) which will be acceptable to the regulatory authorities, the operators, and the manufacturers (Ahmadi, Gupta, Karim, \& Kumar, 2010). This report is intended to preserve the aircraft's inherent safety and reliability levels and, thus, its airworthiness. The developed tasks and their respective intervals are the basis for a first issue of each airline's maintenance requirements. As experience is accumulated throughout the years of operation, additional adjustments in terms of necessary tasks and/or task intervals may be made by the operator together with regulatory institutions to maintain an efficient scheduled maintenance. (Ahmadi, 2010)

Gerdes et al. (2016) describe the practical process as follows: For the determination of required maintenance activities, an industry steering committee (ISC), consisting of authorities, aircraft operators and manufacturer is formed initially. Based on the results of the MSG-3 analysis, MSG working groups (MWGs) develop a MRBR proposal, which then needs to be accepted by the respective authorities (Federal Aviation Administration, 2012). The accepted MRBR is then used by the manufacturer to create the maintenance planning document. The maintenance planning document is specifically designed to aid the planning of maintenance activities for aircraft operators. Additionally, the maintenance planning document may contain diagrams to show locations and numbering of access doors or panels. (Kinnison, 2004) 
An example extract for the Airbus A320 family is given in Tab. 1. The maintenance planning document consists of multiple tasks with intervals - given in either days, FC, or FH - and will be triggered by the threshold occurring first. For some tasks, there is a specific threshold given which specifies the initial interval for the first execution of the respective task. Additionally, the maintenance planning document provides estimates for task execution and preparation times in man hours as guideline for operators. It has to be noted, though, that these times can significantly differ from practical experience (Bill, Roizès, \& Pichon, 2019). Finally, the maintenance planning document provides limitations of application, i.e. specific tasks only apply for certain aircraft configurations. Since the maintenance planning document only contains routine maintenance activities, additional implications by execution of the necessary tasks towards subsequent unscheduled maintenance activities, e.g. a detected fault during a routine functional check may lead to an unplanned necessary system restoration, are also not included in the document.

\subsection{Literature Review}

Since this paper addresses the aspects of maintenance planning optimization under consideration of different technological maturity levels of PHM systems, the state-of-the-art research in these areas is evaluated in order to identify research gaps that will need to be addressed by the developed simulation tool.

\section{Maintenance planning optimization}

There are multiple papers dealing with the optimization of maintenance scheduling in the areas of aircraft operations as well as for physical production sites.

Papakostas, Papachatzakis, Xanthakis, Mourtzis, and Chryssolouris (2010) focus in their paper on maintenance decision making under consideration of resource availability and RUL prediction. They assume that a maintenance engineer has maintenance related tasks to allocate to different maintenance

\begin{tabular}{lc}
\hline Dimension & Value \\
\hline Description & $\begin{array}{c}\text { Wheels - Functional check } \\
\text { of tire pressures }\end{array}$ \\
\hline $100 \%$ Interval & 3 days \\
\hline Men & 1 \\
\hline Task Man Hours & 0.10 \\
\hline Prep. Man Hours & 0 \\
\hline Access Man Hours & 0 \\
\hline Applicability & All \\
\hline
\end{tabular}

Table 1. Tire pressure measurement task for an A320 (Airbus, 2010) stations throughout the daily flight cycle. The overall goal for the optimization is the minimization of maintenance related costs, the increase of operational reliability, and the reduction of flight delays. The engineer's decision shall be based on the planned flight schedule, resource availability at the respective stations, and a known system degradation. Special focus here has been laid on the distinction between GO or NOGO items according to the manufacturer's minimum equipment list (MMEL). This approach, however, does not consider any uncertainty in the RUL prediction stemming from different technology maturity levels, implicitly, neglecting variations of the PH or PA. For Papakostas et al. (2010), the determination of available resources has to be completed at the beginning of daily operation and, therefore, does not incorporate unforeseen changes resulting from missed failure projections of aircraft within the fleet network throughout the day.

Vianna, Rodrigues, and Yoneyama (2015) focus in their paper on planning of line maintenance activities using a heuristic method. Besides the necessary time for the task execution itself, they also consider the process of troubleshooting. Furthermore, factors like resource availability and operational restrictions (e.g. planned flight schedule) are considered in this approach. However, the RUL calculation happens statistically and does not take into account different operational conditions with resulting deterioration rates. Additionally, the resource availability is considered as predetermined input value for this proposed method, which can be hard to obtain in reality, especially for longer planning horizons.

The optimization of scheduled maintenance task allocation to minimize overall costs has been investigated by Hölzel, Schröder, Schilling, and Gollnick (2012). In this paper, they focus on the whole lifecycle of an aircraft to uncover longterm effects of changes in the maintenance planning. Additionally, the proposed approach considers the implementation of PHM technologies and resulting projections of upcoming faults as well as the cost of wasted lifetime by premature part replacement. However, no distinction of different technology maturity levels, i.e. condition monitoring performances, has been made. Furthermore, the model relies on the user input regarding resource availability and estimated health status of the respective systems to generate an optimized maintenance schedule. As previously stated, these information may be hard to obtain in reality for long-term planning and, thus, significantly limit the applicability of the model.

Chen, Xiao, Zhang, Xiao, and Li (2015) developed a methodology to combine production scheduling and preventive maintenance planning for physical production sites which could deliver valuable insides for our research question. They consider in their approach the assignment of different production jobs to multiple available machines. The objective for this method is to assign preventive maintenance tasks or complete system replacements to optimize the overall production 
costs. Chen et al. (2015) also consider the imperfectness of maintenance activities, resulting in shorter utilization cycles and the eventual need for a complete restoration or replacement. Although the proposed concept offers some useful concepts for adaption within an aircraft related environment, the aspect of different deterioration rates - depending on the operating condition - has been neglected. Additionally, is has been assumed that necessary maintenance resources are available whenever needed and, therefore, pose a challenge in real-life applications.

Similar to that approach, Zhai, Riess, and Reinhart (2019) focus on shop floor production sites in their methodology. The proposed optimization model considers time-varying operational conditions with the resulting implications on system degradation and has been introduced as Operation Specific Stress Equivalent (OSSE). This consideration allows a more accurate RUL prognosis and fault projection. Based on the OSSE, Zhai et al. (2019) optimize production cycles to optimally integrate (preventive) maintenance actions within the production. As a result, they can reduce the number of sudden machine failures throughout production and increase the overall process robustness. Although the proposed method offers valuable insights for an application on aircraft operation scheduling, they also do not consider limitations in the availability of required maintenance resources as well as differences in condition monitoring maturity levels.

Approaches and challenges in the transformation from conventional to a prognostic-based aircraft maintenance concept have been discussed by Ismail, Windelberg, and Bierig (2016). Ismail et al. (2016) focus in their study on the operational advantages by implementing prognostic-based maintenance for electro-hydraulic actuators towards minimizing the risk for unscheduled maintenance tasks. They propose a continuous automated health assessment instead of hardtime interval-based, manual functionality checks according to the maintenance planning document. Additionally, they emphasize that a continuous condition-monitoring system must incorporate the information about ambient operating conditions, since these factors can significantly influence the system's performance degradation. However, this paper does not incorporate an estimation of the operational effects, e.g. cost minimization or increased operational stability, by implementation of such a maintenance strategy.

\section{Evaluation of PHM systems}

Besides these approaches of maintenance scheduling optimizations, multiple papers have dealt with the evaluation of the potential of different PHM technologies.

Feldman, Jazouli, and Sandborn (2009) have developed a maintenance decision making approach to determine the expected return on investment for different maturity levels of PHM technologies on the example of a multi-functional dis- play of Boeing's 737. A similar approach has been chosen by Hölzel, Schilling, and Gollnick (2014), who evaluated in their work the potential for introducing PHM concepts in terms of cost savings compared to the conventional maintenance approach for an Airbus A320 using a discrete-event simulation (DES). They are also considering uncertainty in the PHM technology, e.g. missed or false alarm rates, and the percentage of systems covered with condition monitoring technologies. The focus is on a more global, generic perspective of a whole range of aircraft (sub)systems without going into details of specific maintenance tasks. Additionally, the main subject of this study is on cost implications on the aircraft itself, neglecting secondary effects due to adjacent process changes (e.g. a better planning of resource availability).

In contrast, Kählert, Giljohann, and Klingauf (2016) consider the potential implications of PHM technologies for avoidance of unscheduled maintenance events on a detailed component level, specifically for the Air Data Inertial Reference Unit (ADIRU) of Lufthansa's A320 fleet. For this approach, they use empirical maintenance data from Lufthansa as input for the developed discrete-event simulation. As a result, Kählert et al. (2016) can calculate historically incurred maintenance costs and subsequent aircraft delays due to troubleshooting and unexpected rectification tasks. Additionally, minimum requirements in terms of $\mathrm{PH}$ and $\mathrm{PA}$ can be derived from the results to allow for some form of distinction of different technological maturity levels. Since the focus of this work has primarily been on the avoidance of unscheduled maintenance events, the results neglect any savings potential by reducing the amount of regular hard-time, interval-based functional check tasks. Furthermore, aspects of resource limitations and fleet interactions have not been considered in their work.

It has to be noted though, all these existing approaches towards the evaluation of expected benefits with the introduction of PHM technologies almost exclusively focus on cost aspects only. Additionally, all these methods have been developed with a solely asset-centric view, i.e. they focus exclusively on the aircraft itself rather than incorporating secondary effects arising within the involved stakeholders. Thus, the various objectives of the key participants in the airline ecosystem, as presented by Wheeler, Kurtoglu, and Poll (2010), have not been addressed sufficiently so far.

Beyond these economic evaluations of expected benefits, the technological maturity of the developed system itself will need to be described parametrically. The development of metrics to evaluate the performance of various PHM technologies has been subject of multiple research already. Interested readers are kindly referred to the work of Kurtoglu, Mengshoel, and Poll (2008) for the evaluation of diagnosis and Saxena et al. (2008) and Saxena and Roemer (2013) for prognosis technologies. As Vachtsevanos und Goebel (2015) emphasize, the 
continuous improvement of developed diagnostic and prognostic tools requires a framework, which:

- Simultaneously considers all relevant aspects of airline operations and aircraft maintenance, and

- Allows the definition of minimum performance criteria for developed PHM technologies.

Consequently, such a tool will need to utilize the performance metric as parameter input in order to represent different technological maturity levels. As of this paper, we will solely focus on the prognostic horizon to describe a PHM system's technological maturity, as it is arguably the most utilized parameter in the evaluation of prognosis performance (Vachtsevanos, Lewis, Roemer, Hess, \& Wu, 2006).

\section{Research Gaps}

Summarizing, it can be said that multiple methods for developing condition-based maintenance approaches already exist in literature and delivered valuable insights towards maintenance optimization and technology evaluation. However, the following weak spots have been identified:

- Consideration of technology maturity levels

- Consideration of resource availability and utilization

- Consideration of uncertainties in the prediction of failures, i.e. missed alarm rate

- Consideration of different operational loads in aircraft operations

- Consideration of cost saving possibilities for scheduled maintenance

With this paper, we want to address these gaps by developing a simulation tool that enables users to estimate operational impacts of PHM technologies and their respective maintenance strategies depending on the maturity level of the underlying condition monitoring technology, e.g. the automation degree or the prognostic horizon. We will particularly focus on the reduction of average waiting times within a given aircraft fleet for limited ground resources through the introduction of an automated condition monitoring and failure prognosis system. Additionally, we will examine the implications of such a system towards the overall maintenance costs.

\subsection{Estimating the savings potential for task automation}

In order to develop suitable automated condition monitoring technologies, it has to be identified which routine, scheduled maintenance tasks have the highest implications on maintenance operations. These implications will mainly be driven by either a high resource utilization for the task completion or a high frequency of occurrence throughout aircraft operations.

To identify aircraft systems with a high implication on maintenance, we have developed a methodology to generally esti-

\begin{tabular}{lcccc}
\hline Description & $\begin{array}{c}\text { Man } \\
\text { Hours }\end{array}$ & Interval $_{\mathbf{M P D}}$ & Interval $_{\mathbf{F H}}$ & KPI $^{1}$ \\
\hline $\begin{array}{l}\text { Inspection of } \\
\text { cargo compart- } \\
\text { ment }\end{array}$ & 0.65 & $8 \mathrm{DY}^{a}$ & $65.71 \mathrm{FH}^{b}$ & 9.89 \\
\hline $\begin{array}{l}\text { Inspection of } \\
\text { lower half of } \\
\text { fuselage }\end{array}$ & 5.67 & $122 \mathrm{DY}^{a}$ & $1,002.1 \mathrm{FH}^{b}$ & 5.66 \\
\hline $\begin{array}{l}\text { Water drainage } \\
\text { from tanks }\end{array}$ & 0.34 & $10 \mathrm{DY}^{a}$ & $82.14 \mathrm{FH}^{b}$ & 4.13 \\
\hline $\begin{array}{l}\text { Wheels - Pres- } \\
\text { sure check }\end{array}$ & 0.10 & $3 \mathrm{DY}^{a}$ & $24.64 \mathrm{FH}^{b}$ & 4.06 \\
\hline
\end{tabular}

${ }^{a}$ Maintenance interval according to the maintenance planning document.

${ }^{b}$ Maintenance interval converted to $\mathrm{FH}$ equivalent according to annual utilization.

Table 2. Calculation of the operational implication based on an A320's maintenance planning document

mate the savings potential by automating maintenance tasks and, thus, reducing the amount of manual labor required or abolishing it completely. The developed method is based on the information that is available through the maintenance planning document and has been done for an Airbus A320. (Airbus, 2010)

By combining the required man hours for the task completion with the expected frequency of the task to occur during a given time frame, we have developed a key-performance indicator (KPI) to rank maintenance tasks according to their significance towards expected incurring maintenance costs. Since the maintenance planning document contains maintenance intervals specified by either days, FH or FC, as described in section 2.1, we have assumed an annual utilization of 3,000 FH's and an average flight length of $2 \mathrm{FH} / \mathrm{FC}$ to convert all applicable intervals to their corresponding FHequivalent. As a result, this approach delivers the expected required man hours to conduct the respective scheduled maintenance task, normalized to $1,000 \mathrm{FH}$. It has to be noted, though, since all the values refer to information provided by Airbus through the maintenance planning document, they may significantly vary from experience in daily maintenance operations (as described by Bill et al. (2019)). However, as Airbus' A320 is a well established aircraft type and a lot of experience has been introduced with the revisions of its maintenance planning document, the provided values shall provide a good approximation of the reality.

The result of this analysis can be seen in Tab. 2. The provided man hours incorporate besides the estimated servicing time for the described maintenance task itself also times for task preparation and accessing of the respective zones. How-

\footnotetext{
${ }^{1}$ In man hours per 1,000 FH. An average annual utilization of 3,000 FH's with $2 \mathrm{FH}$ per $\mathrm{FC}$ as well as a lifetime of the aircraft of $60,000 \mathrm{FH}$ have been assumed.
} 
ever, additional times for equipment preparation and traveling to the respective aircraft have been neglected. As Kolanjiappan and Maran (2011) indicate for comparable use cases in physical production, this travel time (no-value added) can significantly exceed the actual servicing time (value added) and, thus, influence the saving potential. Additionally, as discussed in the previous subsection, the maintenance planning document only incorporates information about scheduled maintenance activities. Any finding leading to possible subsequent unplanned restoration tasks may increase the amount of manual labor and, therefore, influence the savings potential by an automated condition-monitoring system.

As can be seen, the task with the highest expected implications on maintenance concerns the inspection of the cargo compartment. Despite a comparably small effort in terms of required man hours for task execution, this task has a high operational implication due to its high frequency of occurrence, i.e. an execution interval of 8 calendar days. A complete shift of this task towards full automation would therefore strongly ease the operational planning of the respective maintenance activities. In contrast, the inspection of the lower half of the fuselage has to be completed only every $4^{\text {th }}$ month. However, the task execution takes significantly longer. Therefore, the implication is more driven by the length of resource occupation rather than the frequency of occurrence. Thus, the main aim for these kind of tasks may be in providing technical aiding systems for maintenance personnel for a faster task execution rather than completely automating the task itself.

\subsection{Theoretical layout for automated condition monitor- ing}

We have previously developed a theoretical concept for a full automation of condition-monitoring tasks. (Meissner, Meyer, \& Raddatz, 2019) As of this paper, we will just briefly discuss key aspects of a suitable infrastructure for an effective fault diagnosis, failure prognosis and subsequent maintenance planning optimization without going into much technical detail.

Figure 1 shows the basic layout for such a system. As can be seen, an essential aspect for generating a benefit of an automated condition monitoring system is the transmission of on-board data to a designated ground infrastructure. By combining the on-board sensor data with information about the respective ambient condition, corresponding degradation models, and manufacturer's limitations, an early fault diagnostics and reliable RUL prediction is possible. However, the challenges in data transmission steadily increase with the amount of generated on-board data and the limitations of current transmission technologies (Aircraft Commerce, 2019). Thus, there has to be some instance connected in between, i.e. a data concentrator, to decide about the time of the data

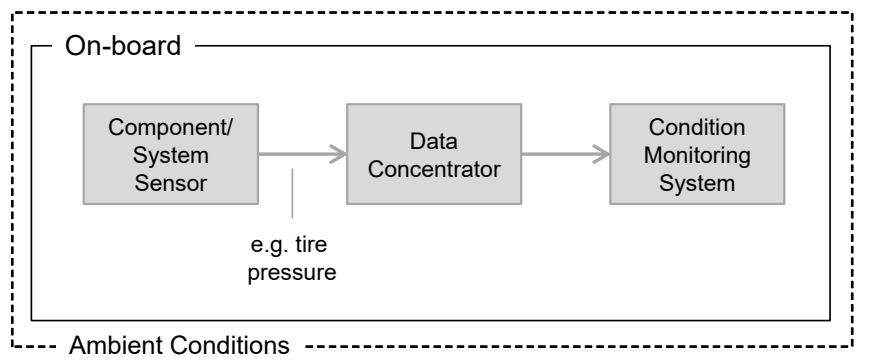

Data Stream

(real-time or

periodically)

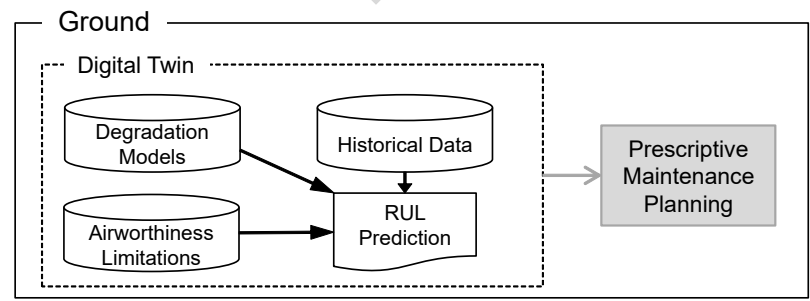

Figure 1. Theoretical system layout, based on Meissner, Raschdorff et al. (2019)

report to be issued and the amount of sensor data to be transferred.

As the amount of available information can have significant influence on the performance of RUL prognosis algorithms, the design of data transmission and measurement frequency can pose a challenge. We have previously examined the influence of changes in the failure prediction performance with changing measurement frequency for the scenario of tire pressure measurement (Meissner, Raschdorff, Meyer, \& Schilling, 2019). Based on these first insights, we will address in this paper the implications of different measurement strategies towards operations and total maintenance cost expenditures.

Eventually, after combining all available relevant information to predict the expected state of degradation, the generated knowledge needs to be taken into account for the respective maintenance decision making process to allow a prescriptive maintenance approach as defined in section 1 . This combination of different aspects of aircraft maintenance enables the full exploitation of benefits by implementing an automated condition monitoring infrastructure.

What has to be mentioned here, as for all applications within the aviation industry, such a layout will need to ensure that the tire pressure is correctly measured and transferred to the ground instance for further computation and reliable calculation of the component's RUL. Meyer et al. (2020) introduced this requirement as part of a digital thread, which will enable the generated data to serve as single source of truth - by ensuring the correct, timely, and complete acquisition of necessary measurement data. This process of correct data 
acquisition will require the consideration of relevant regulatory requirements. This includes in particular the completion of a certified functional check at least every $3^{\text {rd }}$ day of operations (as shown in Tab. 1), the avoidance of flight operations with underinflated tires, and the correct waiting times before pressure measurement to compensate for temperature induced pressure changes.

\section{Use Case Scenario}

For this paper, we focus on the task of tire pressure measurement to examine necessary steps for an automated system condition monitoring. Although other tasks seem to have higher implications on maintenance (ref. Tab. 2), this use case offers the advantage of being limited in its complexity of modeling system degradation while still having high implications on maintenance planning due to the high frequency of scheduled functional check task occurrence. Additionally, the conventional tire pressure reading approach does not require the storage of recorded values for trend analyses or similar during normal operation. (Goodyear, 2017) Thus, a detection of any long-term abnormality of the pressure degradation, i.e. excessive repressurization requirements, is hardly detectable. Furthermore, as can be seen in Fig. 2, subsequent maintenance task decisions depend on the pressure measurement, i.e. the observed condition, and can delay the aircraft's return to service significantly. Therefore, the possibility of early abnormality detection and fault forecasting promise significant easing potential in aircraft operation. (Meissner, Meyer, \& Raddatz, 2019)

\subsection{Tire Pressure Measurement Technology}

Conventional tire pressure measurement consists of a routine, hard-time interval-based inspection cycle of the tire pressure. These measurements are usually performed manually and allow a determination of the tire condition with respect to the manufacturer's instructions (Goodyear, 2017). Depending on the actual pressure read, multiple subsequent maintenance tasks can be triggered, ranging from de-pressurization to a complete tire replacement of the whole axle. The respective decision tree with the applicable limitations is depicted in Fig. 2. Furthermore, operators are required by the manufacturer to wait at least 3 hours after landing for the tire's gas temperature to adjust to the ambient conditions until a reliable pressure measurement is possible (Goodyear, 2017). According to Meyer, Bontikus, and Plagemann (2017), this waiting time exceeds the usual turnaround time of an average narrow-body aircraft and, therefore, practically prevents reliable tire pressure measurements throughout daily operations without operational disruptions.

First approaches for a semi-automated tire pressure measurement in an aerospace application have been proposed by Bill (2016), Bill et al. (2019), and Crane Aerospace (2014).

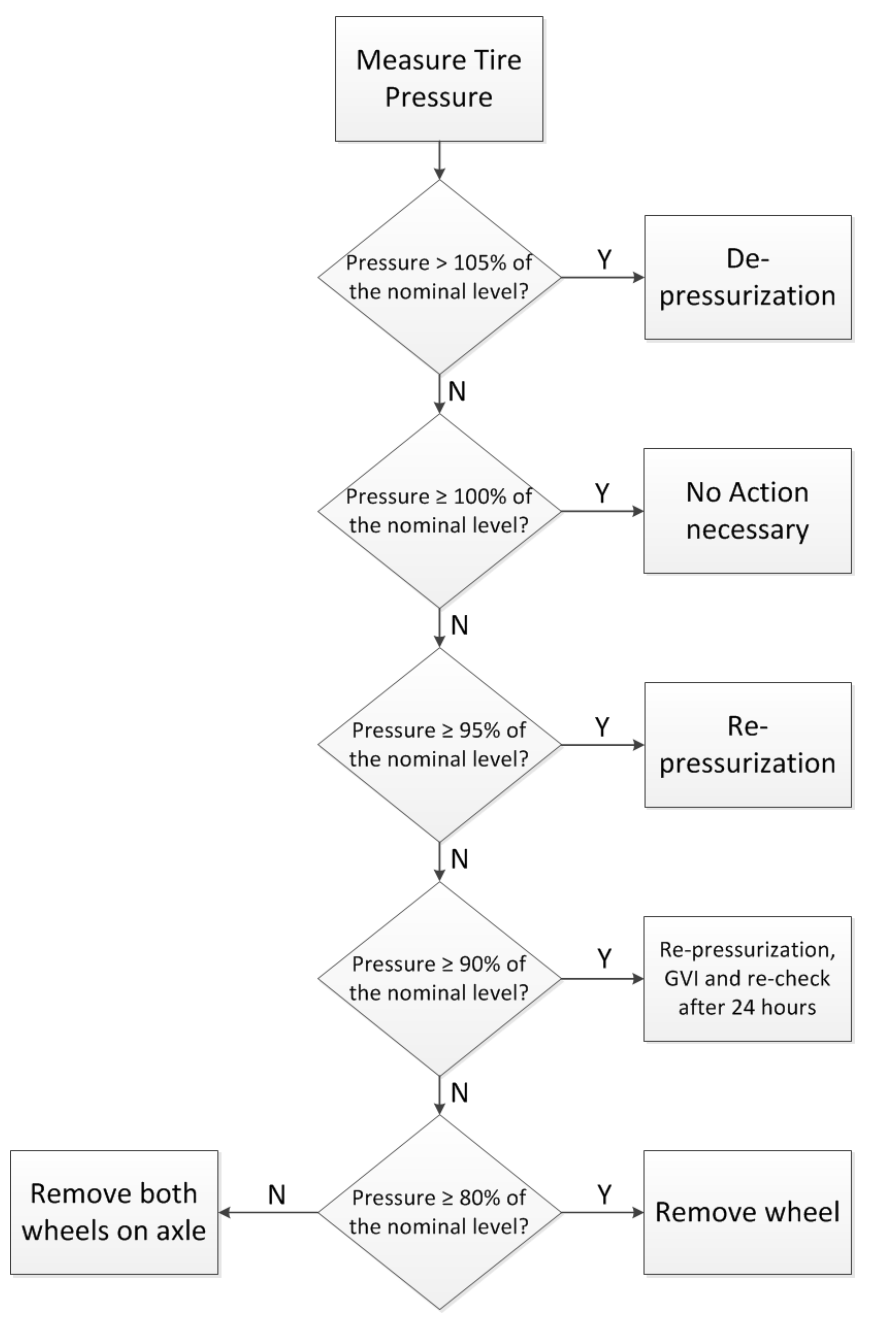

Figure 2. Decision tree for subsequent maintenance task after pressure reading (Goodyear, 2017)

They show the basic feasibility of a wireless data transmission and storage of historical tire pressure data and present potential process improvements by reducing task duration. Bill et al. (2019) follow the approach of wireless transmission of recorded pressure data to designated ground equipment through Bluetooth connection. These devices will then display the recorded pressure values and help the mechanic to decide if further maintenance tasks are necessary. Therefore, the pressure reading task itself remains unchanged and will be technically aided to reduce the task duration. Bill et al. (2019) expect the process time to decrease from $15 \mathrm{~min}$ utes to 1 minute per aircraft. However, these changes will not avoid the manual pressure reading task itself. Therefore, there is still the possibility of unnecessary functional check tasks which do not result in any restoration activities. Furthermore, a long-term fault prognosis can only be established using empirical measurement data from the past in combination with the respective operational load causing the degradation. Both 
these aspects have been neglected by either technology thus far.

As Bill et al. (2019) mention, a valuable contribution to an airline operation and implementation of the developed technology requires a valid business case scenario. In previous work by Yam, Tse, Li, and Tu (2001), Meissner, Meyer et al. (2019), and Papakostas et al. (2010), the main factors for cost savings and, thus, a valid business case have been identified as:

- Abolishing scheduled manual functional checks,

- Avoiding premature part replacement,

- Reducing delay costs,

- Reducing the missed alarm rate,

- Reducing the necessary inventory stock, and

- Increasing the resource availability/utilization.

Therefore, developed condition monitoring technologies need to be evaluated towards these aspects in order to ensure the exploitation of their full potential.

\subsection{Simulation Setup}

In order to evaluate a developed technology towards the previously mentioned key aspects, we use a multi-agent, discreteevent simulation. As Crooks and Heppenstall (2012) describe, the approach of an agent-based modeling (ABM) allows the simulation of individual actions of diverse agents and the measurement of the resulting system behavior and outcomes over time. In this setup, aircraft and ground resources serve as agents that follow a specific work flow. Their actions will be recorded in their respective event calendars and will subsequently be available for evaluating the system's performance.

For this paper, PREMADE (Prescriptive Maintenance Developer), a simulation tool for post-prognostics decisionmaking, has been developed. This tool has been implemented in PYTHON to avoid functional limitations as they would come with commercial software solutions and to allow a certain flexibility in the scope of the analysis. The basic software setup can be seen in Fig. 3. The framework bases on the principle of an initial generation of object entities which provide certain attribute information and autonomously make decisions based on their given functional dependencies. The object initialization relies on the simulation specifications supplied by a user, i.e. a flight rotation plan, maintenance process parameters, and information about the underlying condition monitoring technology with its technological maturity (e.g. measurement interval, maintenance thresholds, or the prognostic horizon). After the objects have been initialized and all simulation agents possess their own timestamp in the universal time coordinated (UTC) format, the simulation will run in a continuous loop until the simulated lifetime matches

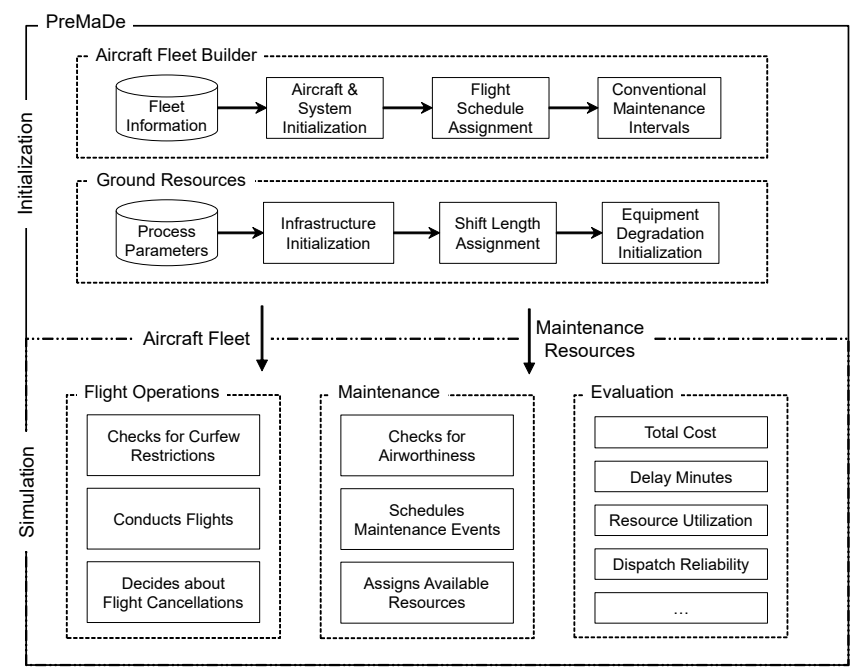

Figure 3. Basic principle of the simulation tool for the development of prescriptive maintenance strategies

the predetermined simulation time span. Within the loop, aircraft objects are chosen according to their current timestamp and will simulate aircraft operation, maintenance scheduling, and, eventually whenever necessary, maintenance task execution. As stated previously, all of the events will be recorded in an agent-specific event calendar and can subsequently be analyzed towards the interactions among the agents within the simulation setup.

To limit the simulation's complexity, the following assumptions have been made for this paper:

$A_{1} \quad$ All aircraft follow a predetermined flight schedule and cannot be substituted among each other.

$\mathrm{A}_{2}$ Maintenance events, i.e. functional checks and restoration tasks, can occur any time throughout the day, but only at designated maintenance hubs.

$\mathrm{A}_{3}$ Travel times for mechanics to get from aircraft A to aircraft $B$ have been neglected.

$\mathrm{A}_{4}$ Aircraft waiting for service will be served on a first come, first served basis.

$\mathrm{A}_{5}$ One ground resource entity, e.g. a mechanic, can only serve one aircraft at a time and will only be occupied for the tire pressure restoration task; thus, the resource will be available when no tire maintenance task within the fleet is due.

$\mathrm{A}_{6}$ Maintenance tasks will be conducted for whole subsystems on an aircraft instead of individual components, e.g. for all nose landing gear tires instead individual tires.

$\mathrm{A}_{7} \quad$ A restoration maintenance task will reset the component to a condition 'as good as new', i.e. individual performance differences for different mechanics resources will be neglected. 
A8 Ground support equipment will always be available when needed and does not experience degradation; therefore, it does not need to be restored.

\subsection{Parameter Input}

For the setup of the simulation objects, we have defined the input parameters shown in Tab. 3. These values will be supplied by the user and can be changed to reflect different systems and maintenance setups within the simulation. In general, the simulation input parameters can be divided in three different categories:

- Process parameters, i.e. information related to the respective maintenance hubs for task completion,

\begin{tabular}{|c|c|c|c|c|}
\hline Group & Parameter & Value & Unit & Description \\
\hline \multirow{9}{*}{ 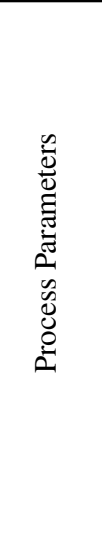 } & $c_{f u n c}$ & $10^{a}$ & $\$$ & $\begin{array}{ll}\begin{array}{l}\text { Cost } \\
\text { check }\end{array} & \text { functional } \\
\end{array}$ \\
\hline & $c_{\text {rest }}$ & $50^{a}$ & $\$$ & Cost restoration \\
\hline & $c_{\text {insp }}$ & $100^{a}$ & $\$$ & Cost inspection \\
\hline & $c_{r e p l}$ & $1,000^{a}$ & $\$$ & Cost replacement \\
\hline & $t_{\text {func }}$ & $01: 00^{b}$ & $\min$. & $\begin{array}{l}\text { Time functional } \\
\text { check }\end{array}$ \\
\hline & $t_{\text {rest }}$ & $10: 00^{b}$ & $\min$. & Time restoration \\
\hline & $t_{\text {insp }}$ & $45: 00^{b}$ & $\min$. & Time inspection \\
\hline & $t_{r e p l}$ & $01: 30^{b}$ & hrs. & Time replacement \\
\hline & $n_{\text {mech }}$ & 1 & - & $\begin{array}{l}\text { No. of mechanics re- } \\
\text { quired for each task }\end{array}$ \\
\hline \multirow{5}{*}{ 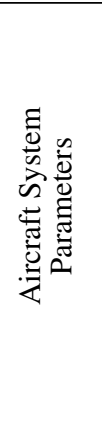 } & $p_{\text {new }}$ & 187 & psi & $\begin{array}{l}\text { Nominal new condi- } \\
\text { tion }\end{array}$ \\
\hline & $t h r_{\text {rest }}$ & $170^{c}$ & psi & $\begin{array}{l}\text { Maintenance thresh- } \\
\text { old restoration }\end{array}$ \\
\hline & $t h r_{i n s p}$ & $161^{c}$ & psi & $\begin{array}{l}\text { Maintenance thresh- } \\
\text { old inspection }\end{array}$ \\
\hline & $t h r_{r e p l}$ & $144^{c}$ & psi & $\begin{array}{l}\text { Maintenance thresh- } \\
\text { old replacement }\end{array}$ \\
\hline & $t_{\text {cool }}$ & 03:00 & hrs. & $\begin{array}{l}\text { Time for the system } \\
\text { to cool down before } \\
\text { maintenance }\end{array}$ \\
\hline \multirow{3}{*}{ 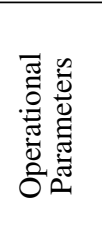 } & $c_{k}^{\text {delay }}$ & 0.25 & $\$$ & $\begin{array}{l}\text { Avg. delay cost } \\
\text { per passenger and } \\
\text { minute }\end{array}$ \\
\hline & $c_{k}^{\text {cancel }}$ & 700 & $\$$ & $\begin{array}{l}\text { Avg. cancellation } \\
\text { cost per passenger }\end{array}$ \\
\hline & $n_{P a x}$ & 180 & {$[-]$} & Seating capacity \\
\hline
\end{tabular}

${ }^{a}$ The maintenance cost for main landing gear tires have been assumed to be $10 \%$ higher.

${ }^{b}$ The process times for main landing gear tires have been assumed to be $20 \%$ higher.

${ }^{c}$ Information about maintenance thresholds is based on data from Goodyear (2017).

Table 3. Simulation input parameter for A320 nose wheel tires

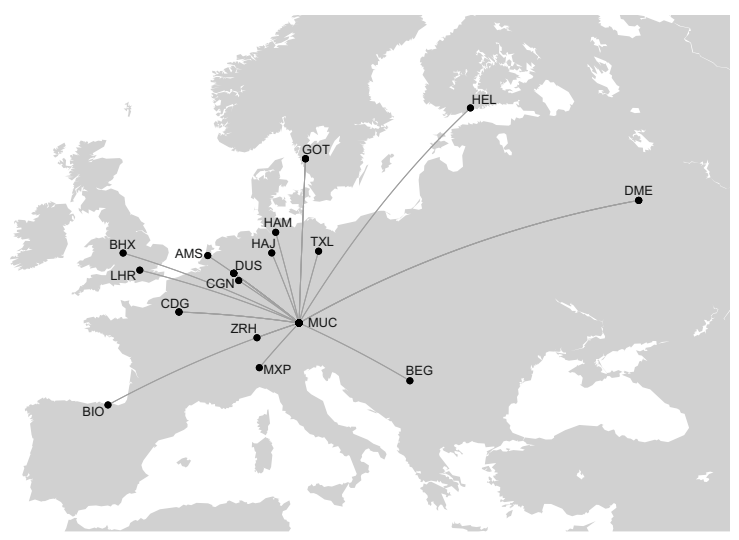

Figure 4. Flight route network for the simulation run

- Aircraft system parameters, i.e. information about maintenance thresholds and the nominal new condition of the selected component, and

- Operational parameters, i.e. information related to the aircraft fleet and operational implications.

The fleet under consideration consists of 5 narrow-body aircraft in short-/medium-haul operation and the simulation period has been selected to a time span of 30 days of operation. This limitation of the simulation period offers the advantage that checks with longer layover downtimes do not need to be accounted for and, therefore, solely the effects of an automated tire condition monitoring task can be examined. Furthermore, it has been assumed that all tire related maintenance tasks have been executed at the beginning of the simulation run and all system states are at their nominal new condition. Since real data about tire pressure degradation was not available as of this paper, we calculated the anticipated tire degradation based on the expected daily pressure loss, the average daily utilization, and the individual flight segment length. As is stated by Goodyear (2017), the maximum allowable daily pressure loss equals $5 \%$. Based on that, we assumed a daily loss average of $3 \%$ with respect to the nominal new condition. Given the average daily utilization - derived from the underlying flight rotation -, we subsequently calculated the expected pressure loss per FH and translated this to the individual tire pressure drop for each flight connection depending on its intended flight duration. The chosen flight rotation network is shown in Fig. 4 and shows the typical layout of an hub-and-spoke carrier.

An excerpt of the used flight rotation plan can be seen in Tab. 4. The individual flight times between the airports are based on historical observations provided by FlightRadar. ${ }^{2}$ As the turnaround times can only be insufficiently retrieved from FlightRadar, we have used a randomly distributed turnaround time with a maximum of 2 hours. The minimum turnaround

\footnotetext{
${ }^{2}$ The historical data can be downloaded from www. flightradar 24 . com and has been retrieved for this study for an exemplary Lufthansa A320 with the registration D-AIPA.
} 


\begin{tabular}{|c|c|c|c|c|c|c|c|c|c|c|}
\hline \multicolumn{5}{|c|}{ Flight Details } & \multicolumn{2}{|c|}{ UTC } & \multicolumn{2}{|c|}{ Local Time } & \multicolumn{2}{|c|}{ Pressure Loss ${ }^{e}$} \\
\hline DATE (UTC) & FROM & TO & TAT $^{a}$ & DUR $^{b}$ & $\mathrm{DEPT}^{c}$ & $\overline{\mathrm{ARVL}^{d}}$ & $\mathrm{DEPT}^{c}$ & $\mathrm{ARVL}^{d}$ & $\mathrm{NLG}^{f}$ & $\mathrm{MLG}^{g}$ \\
\hline 01/01/2020 & MUC & GOT & $00: 45$ & $02: 22$ & 05:00 & $07: 22$ & 06:00 & $08: 22$ & 1.204 & 1.159 \\
\hline 01/01/2020 & GOT & MUC & $01: 45$ & $02: 25$ & 09:07 & $11: 32$ & $10: 07$ & $12: 32$ & 1.230 & 1.183 \\
\hline 01/01/2020 & MUC & CGN & $01: 12$ & 01:33 & $12: 44$ & $14: 17$ & $13: 44$ & $15: 17$ & 0.079 & 0.759 \\
\hline 01/01/2020 & $\mathrm{CGN}$ & MUC & $00: 45$ & 01:42 & $15: 02$ & $16: 44$ & $16: 02$ & $17: 44$ & 0.865 & 0.833 \\
\hline 01/01/2020 & MUC & $\mathrm{CDG}$ & 01:44 & 02:05 & $18: 28$ & $20: 33$ & $19: 28$ & $21: 33$ & 1.060 & 1.020 \\
\hline $01 / 02 / 2020$ & $\mathrm{CDG}$ & MUC & $01: 12$ & $01: 58$ & 04:00 & $05: 58$ & $05: 00$ & $06: 58$ & 1.001 & 0.963 \\
\hline
\end{tabular}

${ }^{a}$ Turnaround Time, ${ }^{b}$ Flight duration, ${ }^{c}$ Departure time, ${ }^{d}$ Arrival time, ${ }^{e}$ in psi, ${ }^{f}$ Nose landing gear, ${ }^{g}$ Main landing gear

Table 4. Exemplary flight rotation excerpt with tire pressure loss for each sub-system and flight segment

time has been estimated, based on a study by Meyer, Bontikous, and Plagemann (2017) for narrow-body aircraft, to be 45 minutes. Additionally, as public information about nonoperating hours for each individual airport within the flight network is sparse, we have estimated the daily curfew hours to begin at $10 \mathrm{pm}$ and end at 6 am of the respective local times. For this simulation, we further assumed that maintenance task execution will solely be possible at the aircraft's home base, i.e. Munich airport. In order to increase the competition for the limited ground maintenance resources and amplify effects of a strictly reactive maintenance planning, all aircraft of the underlying fleet will follow the same flight schedule and, subsequently, will require maintenance at the same time at the designated maintenance base.

\subsection{Prescriptive Maintenance Planning}

After we have defined the use case scenario to be examined in this paper, we want to describe the underlying algorithm for the maintenance scheduling in this section. In contrast to the state-of-the-art maintenance process with its hard-time scheduled functionality checks (as described in section 2.1), the proposed prescriptive maintenance approach aims to project the health status of the corresponding aircraft systems based on automated temperature compensated tire pressure measurements and anticipated future utilization. Thus, we can proactively schedule restoration tasks to preferred time slots based on the expected resource availability at the designated maintenance base to avoid operational irregularities, such as flight delays into the airport's curfew hours (as exemplarily shown in Fig. 5). Subsequently, we expect the waiting times for occupied maintenance resources to reduce with an increased projection time span for necessary maintenance tasks, as the number of possible maintenance opportunities within the reliable projection time span increases and, therefore, allows more flexibility for the task allocation. Consequently, with a reduction of maintenance related downtimes, aircraft operators will be able to increase their assets' utilization rate and reduce subsequent operational irregularity costs, e.g. passenger compensations.

In addition to that, considering upcoming maintenance requirements and adjusting them to the ground resource capabilities will allow to more efficiently utilize the available resources. It has to be noted though that a premature component restoration will lead to an increase of 'waste of life' $\operatorname{costs} c_{s}^{\text {waste }}$, i.e. an artificial restoration cost component that arise from the under-utilization of the component's available degradation margin. These cost can be calculated with

$$
c_{s}^{\text {waste }}=\max \left(0, \frac{h_{s}^{\text {act }}}{h_{s}^{\text {new }}} \cdot c_{s}^{\text {task }}\right)
$$

where $h_{s}^{\text {new }}$ represents the health index for new or completely overhauled sub-systems and $h_{s}^{a c t}$ the actual health index remaining when the maintenance task has been scheduled/conducted. As of this paper, we define the task $\operatorname{cost} c_{s}^{t a s k}$ in Eq. 1 as the minimal necessary cost for restoring the system to its operating condition, i.e. tire repressurization with no detailed inspection or part replacements. Since it is possible for some systems to operate beyond their first restoration threshold and experience further degradation, e.g. tire pressure that leads to detailed inspections or part replacements, the health index $h_{s}^{a c t}$ could mathematically be negative. As this would result in negative 'waste of life' costs and would endorse operators to postpone maintenance tasks, we define a lower limit of $\$ 0$ for $c_{s}^{\text {waste }}$. The expected maintenance costs are the result of incurring costs by execution of the task itself $c_{s}^{\text {task }}$ (according Tab. 3). The expected waiting $\operatorname{costs} c_{k}^{\text {wait }}$ result from the operational delay by waiting for maintenance resources to become available for task execution. The waiting costs are defined on an aircraft level using the following equation (Hölzel, 2019):

$$
c_{k}^{\text {wait }}=c_{k}^{\text {delay }} \cdot n_{\text {Pax }} \cdot l_{\text {Pax }} \cdot t_{\text {ops }}^{\text {delay }}
$$

with $c_{k}^{\text {delay }}$ as the average delay cost per passenger and minute of delay, $n_{P a x}$ as the maximum seating capacity of the 


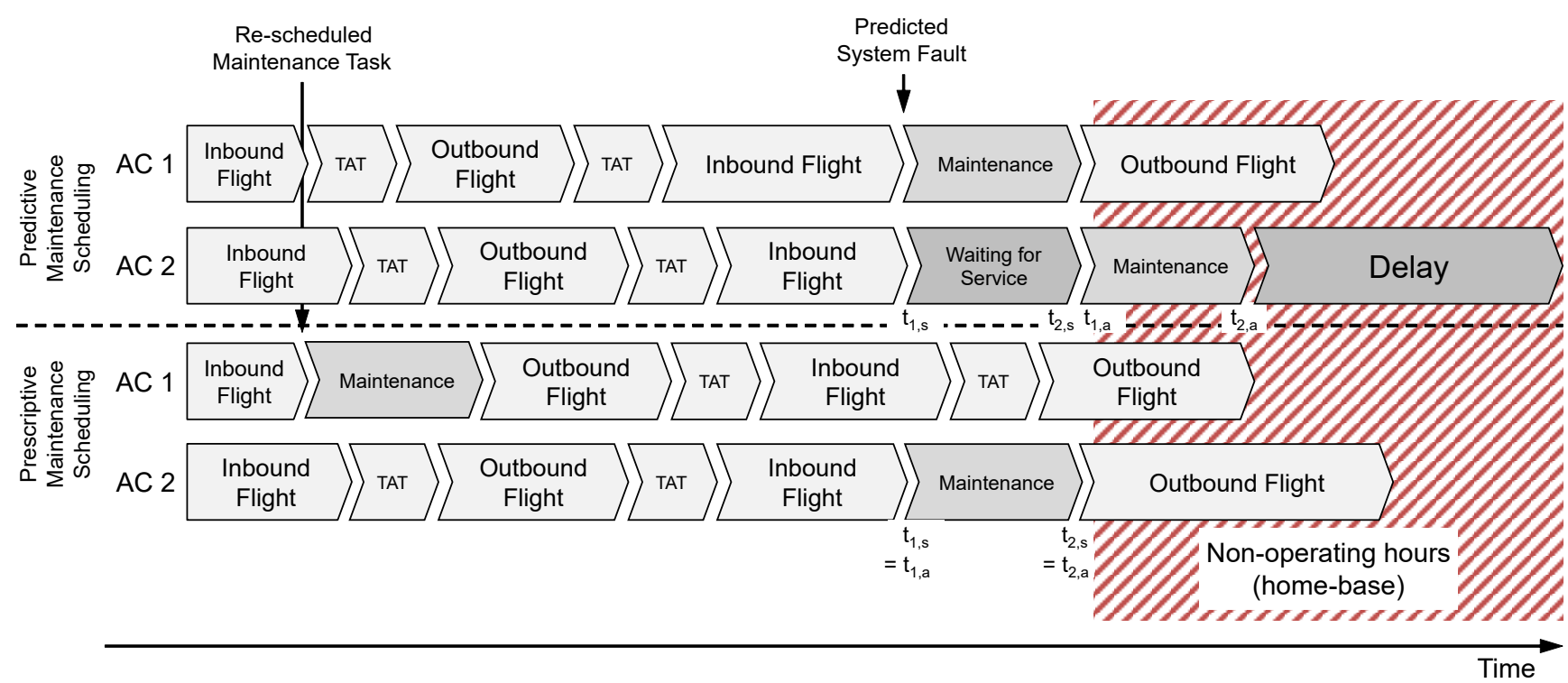

Figure 5. Schematic prescriptive maintenance planning

aircraft, $l_{P a x}$ as the average passenger load factor, and $t_{\text {ops }}^{\text {delay }}$ as the operational delay minutes resulting from delayed maintenance. The resulting operational delay $t_{\text {ops }}^{\text {delay }}$ from delayed maintenance service depends on the time of their occurrence throughout daily operation and will need to be accumulated for every successive flight segment until a longer layover, e.g. during non-operating hours, allows the compensation for the incurred delay.

\section{Simulation Results}

As initially stated, we want to analyze with this paper the implications on different levels of maintenance operations, i.e. available daily maintenance slots (24 hrs., 16 hrs., or $8 \mathrm{hrs}$. daily), on parameters such as the average waiting times for ground service or the average fleet utilization. Additionally, we estimate the benefits with the introduction of an automated condition monitoring system and the application of prescriptive maintenance strategies for different levels of technology maturity. Therefore, we define the following scenarios and benchmark these against the state-of-the-art maintenance approach.

The current approach consists of manual tire pressure checks, conducted with a hard-time interval every $3^{\text {rd }}$ day of operation. This approach complies with the maintenance planning document and serves as our baseline scenario. Starting from this baseline, we have defined the following alternative maintenance approaches:

- Scenario 1: Leaving the approach of regular, manual functional checks - conducted with hard-time intervals unchanged, we have altered the measurement frequency to execute this task on a daily basis.
- Scenario 2: The measurement frequency will be increased further to once every flight cycle. As the maintenance tasks can only be executed at the designated maintenance base in Munich, this measurement frequency can solely be achieved with the help of an automated condition monitoring system, which does not require any ground resources for the functional check tasks. However, these automated functional checks will still require a cool-down time before measurement (ref. Tab. 3).

- Scenario 3: The maintenance task execution will be based on the projection of necessary restoration tasks, i.e. RUL predictions. This implicitly requires regular, temperature compensated functional checks, i.e. without the necessary cool-down time before task execution. However, we assume that before a restoration task can be conducted, the conventional cool-down time of $3 \mathrm{hrs}$. will be required to enable the correct pressurization without any temperature induced inaccuracies.

By defining these scenarios, the safe aircraft operation can be ensured at any time as the measurement interval will be shorter than the conventionally required interval (for all scenarios) and - in particular for scenario 3 - aircraft operation with underinflated tires will be prevented with the reliable projection of remaining useful lifetimes (as discussed in section 2.4).

We first have examined how the average total waiting times for ground maintenance resources changes with the different measurement intervals for the conventional maintenance approach (scenario 1 and 2; ref. Fig. 6) and for the proactive maintenance approach (scenario 3; ref. Fig. 7), respectively. It has to be noted here that the shown values are the sum of 


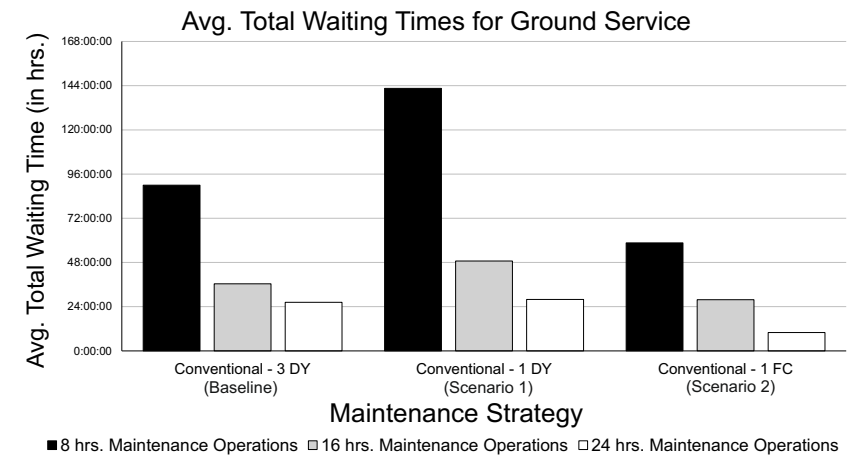

Figure 6. Average total waiting times for ground resources per aircraft over the simulation span for conventional maintenance approaches

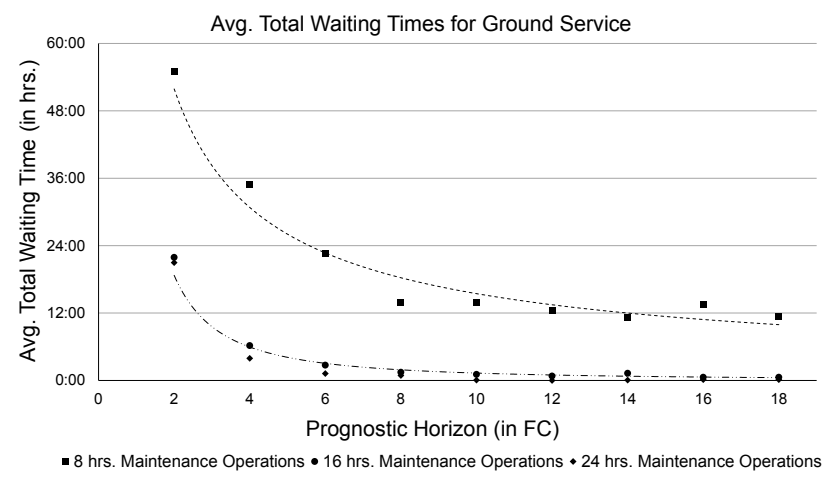

Figure 7. Average total waiting times for ground resources per aircraft over the simulation span for proactive maintenance approach (Scenario 3)

all waiting times over the simulation period for an average aircraft. Thus, the waiting time for a singular maintenance downtime will be significantly shorter. By focusing on the total waiting times, the shown values, therefore, implicitly incorporate the number of maintenance downtimes as well.

As can be seen in Fig. 6 and Fig. 7, while the average waiting times do not change much between the settings of a 24 hrs. maintenance operation to $16 \mathrm{hrs}$. maintenance operations, these values increase drastically for a further reduction of servicing times towards 8 hrs. maintenance operations daily. Further, for the conventional maintenance approach, an increase of the functional check frequency - from every $3^{\text {rd }}$ day to a daily basis - will lead to an increase of average waiting times as the amount of manual maintenance tasks to be handled increases significantly (ref. Fig. 6). By automating the tire pressure measurement task (ref. Scenario 2), the total amount of maintenance tasks decrease - even though the measurement frequency increases to intervals of one flight cycle. Subsequently, this automation will ultimately lead to a reduction of average waiting times for ground resources. For the proactive maintenance approach (ref. Fig. 7), these waiting times significantly depend on the prognostic performance of the underlying PHM technology. As it is shown, with an increase of the prognostic horizon, expressed through the number of flight cycles after the first reliable projection until the restoration task is needed, the average waiting time decreases considerably. Furthermore, it can be seen that an improvement of the prognostic horizon beyond 8 flight cycles does not yield significant improvements in terms of average waiting times. Thus, it appears that the resulting maintenance opportunities from this projection time span sufficiently enables the prescriptive maintenance scheduling algorithm to avoid collisions in task execution times and, ultimately, reduce waiting times for services.

Beyond the effect on waiting times for ground resources, we have estimated the expected influence for the average maintenance cost on each of these maintenance strategies (ref. Fig. 8 ). The conventional maintenance approach and functional check frequency has been set as reference and the average cost for each aircraft over the simulation span of 30 days has been calculated with respect to this baseline. As the maintenance costs do not change much for the different technological maturity levels of the proactive maintenance approach, i.e. varying prognostic horizons, the saving potential for the average cost of the proactive approach will be used subsequently. Additionally, since we have seen in Figs. 6 and 7 that the adversarial effect of a reduction of maintenance operation times to $8 \mathrm{hrs}$. daily seems to be significant, we have focused for the maintenance cost comparison on $16 \mathrm{hrs}$. and $24 \mathrm{hrs}$. maintenance operations, respectively. With the chosen average daily pressure drop and the given aircraft utilization, there are two main effects towards a reduction in maintenance cost:

- the avoidance of maintenance tasks that are beyond the mere pressurization, while

- limiting the amount of manual functional check tasks.

In particular for Scenario 1, with its frequent manual functional checks, the adversarial effect of the latter can be observed. Thus, by choosing an automated condition monitoring approach that can ensure the tire pressure to stay within

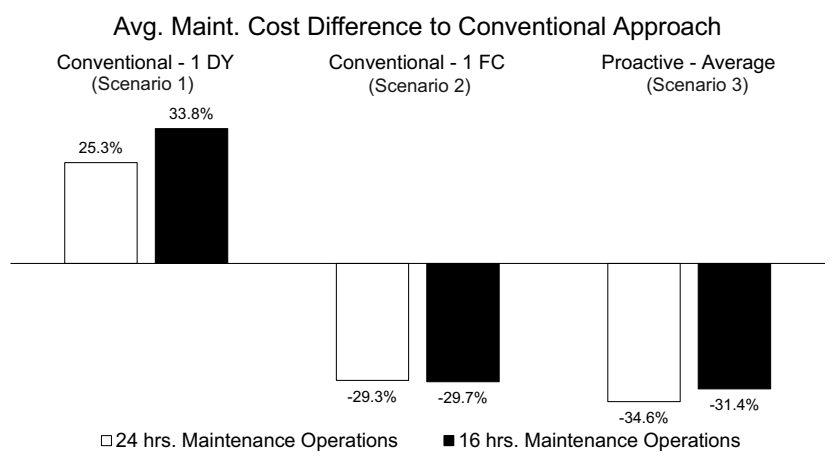

Figure 8. Comparison of average maintenance cost compared to conventional maintenance approach 
the limits for quick - and comparably cheap - repressurizations, there is only a minor additional cost saving potential by projecting maintenance needs (ref. Scenario 2 and 3 in Fig. 8).

However, going beyond these cost effects, we can see in Fig. 9 the effect of the different strategies towards the average fleet utilization. The fleet utilization is expressed as percentage of completed flights in relation to the maximum possible number of flights with the given flight schedule and curfew restrictions. As can be seen, the average fleet utilization decreases with an increase of the functional check frequency. This can mainly be attributed to the mandatory cool-down time before every conventional tire pressure check, leading to comparably long maintenance related downtimes, regularly exceeding the originally intended turnaround time. With the elimination of these cool-down times for the proactive maintenance approach, the fleet utilization virtually recovers completely and matches the utilization degree of the conventional three day maintenance task interval. The slight difference can be explained through the more frequent restoration task in order to avoid aircraft operation with underinflated tires. Thus, besides the measurement frequency and automation of the functional check task, one will need to consider the reduction of necessary cool-down times, specifically through implementation of temperature compensation functions (as discussed by Bill, Roizès, and Pichon (2019)), for an increase of the average fleet utilization. Ultimately, in order to be beneficial over the current, legacy maintenance approach, a continuously monitored system will need to have adjusted restoration limits. Since the risk of an undetected underinflation will be reduced through the continuous measurement, the requirements for existing safety margins within the system, i.e. the current maintenance thresholds, will need to be critically evaluated and adapted accordingly.

Finally, we have examined the effects of the different maintenance strategies towards the degree of resource utilization at the designated maintenance base (ref. Tab. 5). The resource

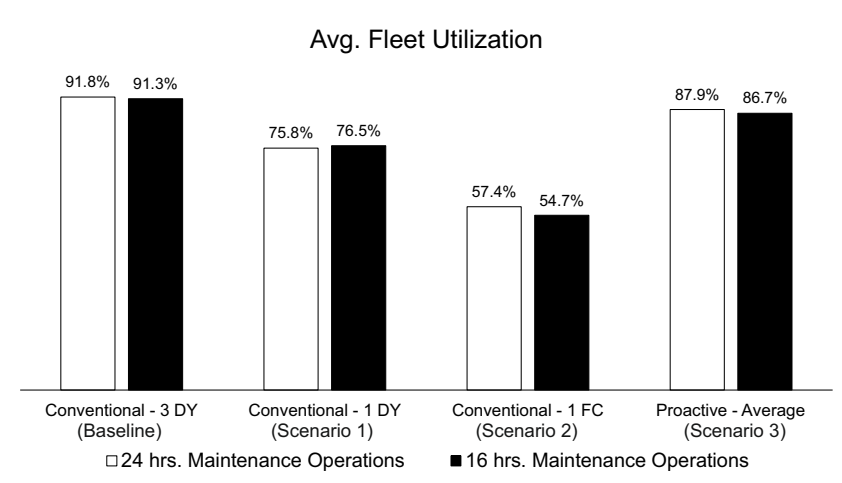

Figure 9. Average fleet utilization for different maintenance approaches

\begin{tabular}{crr}
\hline \multirow{2}{*}{ Maintenance Approach } & \multicolumn{2}{c}{ Resource Utilization } \\
\cline { 2 - 3 } & absolute & relative $^{a}$ \\
\hline Baseline & $10.02 \%$ & - \\
\hline Scenario 1 & $10.05 \%$ & +0.49 \\
\hline Scenario 2 & $8.42 \%$ & -1.60 \\
\hline Scenario 3 & $7.33 \%$ & -2.69 \\
\hline
\end{tabular}

(a) 24 hrs. maintenance operations

\begin{tabular}{crr}
\hline \multirow{2}{*}{ Maintenance Approach } & \multicolumn{2}{c}{ Resource Utilization } \\
\cline { 2 - 3 } & absolute & relative $^{a}$ \\
\hline Baseline & $11.88 \%$ & - \\
\hline Scenario 1 & $13.39 \%$ & +1.51 \\
\hline Scenario 2 & $10.29 \%$ & -1.59 \\
\hline Scenario 3 & $9.40 \%$ & -2.48 \\
\hline
\end{tabular}

(b) 16 hrs. maintenance operations

${ }^{a}$ compared to conventional approach according to maintenance planing document, in percentage points (PP)

Table 5. Resource utilization for different technological maturity levels of a condition monitoring system

utilization is expressed as the ratio of the time the available resources are occupied with maintenance tasks and the total operating time of the designated maintenance base. It has to be kept in mind that we exclusively examine the task of tire pressure measurement and restoration; thus, there are no competing other tasks that will keep the maintenance resources occupied. Unsurprisingly, the resource utilization increases with a reduction of maintenance operating times (comparison of Tab. 5a and 5b) and decreases with an increase of the degree of task automation (comparison of Baseline/Scenario 1 with Scenario 2/Scenario 3). Consequently, the proactive maintenance approach with its high degree of tire pressure management task automation and minimization of restoration tasks will yield the lowest resource utilization (ref. Scenario 3).

\section{Conclusion}

We have shown in this paper an approach to develop and evaluate a prescriptive maintenance strategy for an automated tire pressure condition monitoring technology. Since the saving potential is directly connected to the technology maturity level, we have considered different scenarios with varying levels of automation and prognostic capabilities. As of this paper, we have exclusively focused on the prognostic horizon as the key parameter to describe the maturity level of a PHM system for tire pressure management.

After an initial review of state-of-the-art aircraft maintenance and research in topics of maintenance planning optimization, technology evaluation, and condition monitoring techniques, we have identified multiple research gaps. Specifically, the aspects of technology maturation, resource availability, un- 
certainty in failure projection, and cost saving potential for scheduled maintenance have hardly been a topic of consideration, thus far, and have never been combined for a holistic strategy development and evaluation before.

With that knowledge, we have presented a methodology to estimate implications for maintenance operation for scheduled maintenance tasks in the maintenance planning document. This method can be used to identify maintenance tasks with high savings potential by task automation. Based on this approach, we have identified the task of tire pressure measurement for implementation of an automated condition monitoring technology, since it has a high frequency of occurrence and, therefore, a high impact on the routine maintenance operation.

We further have presented a theoretical layout of a possible condition monitoring system without going into much technical detail and rather focusing on the key aspects of such a system for an holistic maintenance decision making approach. We have emphasized that an automated condition monitoring technology needs to ensure the consideration of ambient conditions leading to the observed system degradation. Additionally, such a system needs to provide a smart maintenance decision support model to fully exploit the technological benefits, while assuring the correct functionality within the system's limitations defined by the manufacturer.

For the underlying agent-based, discrete-event simulation, we have made multiple assumptions to limit the simulations complexity. For example, we have assumed that all aircraft follow a predetermined flight schedule and maintenance events can occur at any given time during daily operation. Additionally, we have neglected the travel times for mechanics to get from one aircraft to another as well as any imperfections of maintenance tasks. Finally, we have assumed that maintenance will be conducted for the whole system and will not be limited to selected sub-systems. The consideration of any uncertainties about ambient conditions, e.g. suspended operations due to thunderstorms, have not been part of this paper.

We have shown that a prescriptive maintenance strategy can deliver a significant potential for the reduction of waiting times for necessary ground resources. We have demonstrated in particular the changes in waiting times for different prognostic horizons, so that optimal performance criteria for a proactive tire pressure management system could be derived. Furthermore, we have shown that the evaluation of developed PHM systems shall extend its scope beyond the mere consideration of cost aspects by adding the parameters of maintenance resource and fleet utilization. However, all of these saving potentials are strongly dependent of the underlying assumed tire degradation model and the given flight schedule. Future work should therefore concentrate on improving a dependable tire degradation model, based on observable ambient conditions, for reliable results. Additionally, other param- eters have to be also considered for future work in order to develop a holistic simulation of all involved stakeholders. These parameters could include the resilience of maintenance planning against changing operating conditions, e.g. a temporary suspension of airline operations at the maintenance base due to severe weather conditions, or additional technological maturity parameters, such as the missed alarm rate or the prognostic accuracy. Additionally, it will need to be examined in future work how different tasks for various systems can be efficiently combined to increase the resource utilization while minimizing conflict scenarios, i.e. situations where multiple aircraft compete for the same limited ground resource. Finally, as we have assumed the whole fleet to be operated with the same maintenance strategy, next development steps will need to include different levels of technological maturity within the fleet in order to identify minimum maturation levels with an increased number of aircraft operating with the respective system.

\section{NOMENCLATURE}

$\begin{array}{ll}A B M & \text { agent based modeling } \\ A D I R U & \text { air data inertial reference unit } \\ D E S & \text { discrete-event simulation } \\ D Y & \text { day(s) } \\ F C & \text { flight cycle(s) } \\ F H & \text { flight hour(s) } \\ I S C & \text { industry steering committee } \\ K P I & \text { key performance indicator } \\ M M E L & \text { manufacturer's minimum equipment list } \\ M R B R & \text { maintenance review board report } \\ M S G & \text { maintenance steering group } \\ M W G & \text { MSG working group } \\ O S S E & \text { operation specific stress equivalent } \\ P A & \text { prognostic accuracy } \\ P H & \text { prognostic horizon } \\ R C M & \text { reliability-centered maintenance } \\ R U L & \text { remaining useful lifetime } \\ S H M & \text { structural health monitoring } \\ T P I S & \text { tire pressure indication system } \\ U T C & \text { universal time coordinated }\end{array}$

\section{REFERENCES}

Ahmadi, A. (2010). Aircraft scheduled maintenance programme development: Decision support methodologies and tools (Unpublished doctoral dissertation). Luleå University of Technology, Luleå.

Ahmadi, A., Gupta, S., Karim, R., \& Kumar, U. (2010). Selection of maintenance strategy for aircraft systems using mulit-criteria decision making methodologies. International Journal of Reliability, Quality and Safety Engineering, 17(03), 223-243. doi: 10.1142/ S0218539310003779 
Airbus. (2010). Maintenance planning document a320 rev. 34.

Aircraft Commerce. (2019). Airline results of using big data \& predictives. Aircraft Commerce(125), 36-42.

Bill, A. (2016). Aircraft tire pressure monitoring system (No. US20170087943A1).

Bill, A., Roizès, J., \& Pichon, B. (2019). Wireless tire pressure indication system for aircraft. 7th International Workshop on Aircraft System Technologies, 7, 89-98.

Chen, X., Xiao, L., Zhang, X., Xiao, W., \& Li, J. (2015). An integrated model of production scheduling and maintenance planning under imperfect preventive maintenance. Eksploatacja i Niezawodnosc-Maintenance and Reliability, 17(1), 70-79. doi: 10.17531/ein.2015 .1 .10

Chiachío, J., Chiachío, M., Saxena, A., Rus, G., \& Goebel, K. (2013). An energy-based prognostic framework to predict fatigue damage evolution in composites. In PHM Society (Ed.), Proceedings of the annual conference of the prognostics and health management society 2013 (pp. 363-371). Retrieved 2020-04-06, from https://www.phmsociety.org/sites/ phmsociety.org/files/phm_submission/ 2013/phmc_13_050.pdf

Crane Aerospace \& Electronics. (2014). Tire pressure and brake temperature systems. Crane Aerospace \& Electronics. Retrieved 29.01.2020, from https:// www. craneae.com/Products/Sensing/ Downloads/SmartStem\%200nBoard\%20737\% 20Max.pdf

Crooks, A. T., \& Heppenstall, A. J. (2012). Introduction to agent-based modelling. In A. J. Heppenstall, A. T. Crooks, L. M. See, \& M. Batty (Eds.), Agentbased models of geographical systems (Vol. 238, pp. 85-105). Dordrecht: Springer Netherlands. doi: 10.1007/978-90-481-8927-4\{\textunderscore $\} 5$

Deutsches Intstitut für Normung e.V. (2010). Din en 13306:2010 maintenance: Maintenance terminology. Deutsches Institut für Normung e.V.

Federal Aviation Administration. (2012). Advisory circular: Maintenance review boards, maintenance type boards, and oem/tch recommended maintenance procedures: Ac 121-22c.

Feldman, K., Jazouli, T., \& Sandborn, P. A. (2009). A methodology for determining the return on investment associated with prognostics and health management. IEEE Transactions on Reliability, 58(2), 305-316. doi: 10.1109/TR.2009.2020133

Freeman, F. (2019). Challenges and opportunities for condition-based adaptive aircraft maintenance planning. Zürich. Retrieved from https:// www.smartmaintenance.ch/doc/Folien/ [PS1]_1-1_Freeman_Challenges $\% 20$ and\% 20 pportunities\%20for\%20Condition
-based\%20Adaptive\%20Aircraft\%

20Maintenance $20 \mathrm{Planning} \cdot$ pdf

Gerdes, M., Scholz, D., \& Galar, D. (2016). Effects of condition-based maintenance on costs caused by unscheduled maintenance of aircraft. Journal of Quality in Maintenance Engineering, 22(4), 394-417. doi: 10.1108/JQME-12-2015-0062

Goodyear. (2017). Aircraft tire care \& maintenance. Retrieved 10.12.2018, from https:// www.goodyearaviation.com/resources/ pdf/aviation_tire_care_3_2017.pdf

Hölzel, N. (2019). Ein bewertungsansatz zur analyse von zustandsmanagementsystemen in verkehrsflugzeugen unter berücksichtigung neuer instandhaltungskonzepte (PhD Thesis, DLR). doi: 10.15480/882.2543

Hölzel, N., Schilling, T., \& Gollnick, V. (2014). An aircraft lifecycle approach for the cost-benefit analysis of prognostics and condition-based maintenance based on discrete-event simulation. In PHM Society (Ed.), Annual conference of the prognostics and health management society 2014 (Vol. 5, pp. 116). Retrieved 06.12.2018, from https://www . phmsociety.org/node/1297

Hölzel, N., Schröder, C., Schilling, T., \& Gollnick, V. (2012). A maintenance packaging and scheduling optimization method for future aircraft. In 6th international meeting for aviation product support processes (imapp). Retrieved from https://elib.dlr.de/76244/

Ismail, M., Windelberg, J., \& Bierig, A. (2016). A potential study of prognostic-based maintenance for primary flight control electro-mechanical actuators. 7th Conference on Recent Advances in Aerospace Actuation Systems and Components, 7, 1-8. Retrieved 20.11.2019, from https://elib.dlr.de/103578/

Kählert, A., Giljohann, S., \& Klingauf, U. (2016). Costbenefit analysis and specification of component-level phm systems in aircraft. Universal Journal of Mechanical Engineering, 4(4), 88-98. doi: 10.13189/ ujme.2016.040403

Kinnison, H. A. (2004). Aviation maintenance management. New York: McGraw-Hill.

Kolanjiappan, S., \& Maran, K. (2011). Lean philosophy in aircraft maintenance. Journal of Management Research and Development, 1, 27-41.

Kurtoglu, T., Mengshoel, O. J., \& Poll, S. (2008). A framework for systematic benchmarking of monitoring and diagnostic systems. In 2008 international conference on prognostics and health management (pp. 113). IEEE. doi: 10.1109/PHM.2008.4711454

Loutas, T., Eleftheroglou, N., \& Zarouchas, D. (2017). A data-driven probabilistic framework towards the insitu prognostics of fatigue life of composites based on acoustic emission data. Composite Structures, 161, 522-529. doi: 10.1016/j.compstruct.2016.10.109 
Meissner, R., Meyer, H., \& Raddatz, F. (2019). A measurement frequency estimation method for failure prognosis of an automated tire condition monitoring system. 2019 IEEE International Conference on Prognostics and Health Management, 1-8. doi: 10.1109/ ICPHM.2019.8819422

Meissner, R., Raschdorff, F., Meyer, H., \& Schilling, T. (2019). Digital transformation in maintenance on the example of a tire pressure indicating system. In O. von Estorff \& F. Thielecke (Eds.), Proceedings of the 7th international workshop on aircraft system technologies (pp. 99-108). Herzogenrath: Shaker.

Meyer, H., Bontikous, N., \& Plagemann, A. (2017). Development of an end to end maintenance evaluation strategy for new technologies in the context of ivhm. Proceedings of the 6th Aeropsace Europe CEAS Conference, 6, $1-10$.

Meyer, H., Zimdahl, J., Kamtsiuris, A., Meissner, R., Raddatz, F., Haufe, S., \& Bäßler, M. (2020). Development of a digital twin for aviation research. In Deutsche Gesellschaft für Luft- und Raumfahrt (Ed.), Deutscher luft- und raumfahrtkongress 2020.

Nemeth, T., Ansari, F., Sihn, W., Haslhofer, B., \& Schindler, A. (2018). Prima-x: A reference model for realizing prescriptive maintenance and assessing its maturity enhanced by machine learning. Procedia CIRP, 72, 1039-1044. doi: 10.1016/j.procir.2018.03.280

Papakostas, N., Papachatzakis, P., Xanthakis, V., Mourtzis, D., \& Chryssolouris, G. (2010). An approach to operational aircraft maintenance planning. Decision Support Systems, 48(4), 604-612. doi: 10.1016/j.dss.2009.11 .010

Poole, K. (2015). Modellbasierte entwicklung eines systems zur zustandsdiagnose und -vorhersage für die hydraulische energieversorgung in verkehrsflugzeugen (PhD Thesis). TUHH, Hamburg.

Ritter, O., Wende, G., Gentile, R., Marino, F., Bertolino, A., Raviola, A., \& Jacazio, G. (2018). Intelligent diagnostics for aircraft hydraulic equipment. In PHM Society (Ed.), Proceedings of the european conference of the phm society (Vol. 4).

Saxena, A., Celaya, J., Balaban, E., Goebel, K., Saha, B., Saha, S., \& Schwabacher, M. (2008). Metrics for evaluating performance of prognostic techniques. In 2008 international conference on prognostics and health management (pp. 1-17). IEEE. doi: 10.1109/ PHM.2008.4711436

Saxena, A., \& Roemer, M. (2013). Ivhm assessment metrics. In I. K. Jennions (Ed.), Integrated vehicle health management (pp. 107-127). Warrendale: SAE International.

Vachtsevanos, G., \& Goebel, K. (2015). Introduction to prognostics. San Diego, USA. Retrieved from http:// wWw. phmsociety.org/sites/phmsociety
. org/files/PROGNOSTICS_TUTORIAL.pdf

Vachtsevanos, G., Lewis, F., Roemer, M., Hess, A., \& Wu, B. (Eds.). (2006). Intelligent fault diagnosis and prognosis for engineering systems. Hoboken, N.J.: John Wiley.

Vianna, W. O. L., Rodrigues, L. R., \& Yoneyama, T. (2015). Aircraft line maintenance planning based on phm data and resources availability using large neighborhood search. 2015 Annual Conference of the Prognostics and Health Management Society, 1-7.

Wheeler, K. R., Kurtoglu, T., \& Poll, S. D. (2010). A survey of health management user objectives related to diagnostic and prognostic metrics. In 29th computers and information in engineering conference (pp. 1287-1298). New York, N.Y.: ASME. doi: 10.1115/ DETC2009-87073

Yam, R. C. M., Tse, P. W., Li, L., \& Tu, P. (2001). Intelligent predictive decision support system for condition-based maintenance. The International Journal of Advanced Manufacturing Technology, 17(5), 383-391. doi: 10 $.1007 / \mathrm{s} 001700170173$

Zhai, S., Riess, A., \& Reinhart, G. (2019). Formulation and solution for the predictive maintenance integrated job shop scheduling problem. 2019 IEEE International Conference on Prognostics and Health Management, 1-8. doi: 10.1109/ICPHM.2019.8819397

\section{BIOGRAPHIES}

Robert Meissner is a researcher at the Institute of Maintenance, Repair and Overhaul within the German Aerospace Center (DLR). He currently pursues his Ph.D. as a member of the product lifecycle management group. His research interest lies in the estimation of operational impacts and economic assessments of new PHM technologies as well as prescriptive aircraft maintenance strategies. Prior to joining DLR, he has worked in different projects with Lufthansa Technik to develop preventive maintenance concepts for primary flight actuating systems. He received a Master degree in Industrial Engineering and Management in 2017 as well as a Bachelor degree in Transport Systems in 2017, both from the Technical University Berlin.

Hendrik Meyer has studied aircraft design at the University of Applied Science in Hamburg and received a Master degree in business administration at the AKAD University Stuttgart. He has been a researcher with DLR since 2014. Currently, he is a member of the process optimization and digitalization group at the Institute of Maintenance, Repair and Overhaul. Before joining DLR, he has worked many years for different departments within Lufthansa Technik. For the last two years, he has been responsible for the development of operator maintenance programs for different customers. His research mainly focuses on the field of maintenance system development, particularly on the transformation from preventive to predictive maintenance.

Dr. Kai Wicke is the head of the department for product lifecycle management at the Institute of Maintenance, Repair and Overhaul within DLR. He received his diploma degree in Aeronautical and Aerospace Engineering from the Tech- 
nical University of Berlin in 2009 and holds a Ph.D. from the Hamburg University of Technology. His research focuses on the assessment of aerodynamic technologies on air transportation system level with respect to economic and ecological impacts. Due to his deeply contextual work contribution and assignment as (sub-)coordinator in internal, national and
European projects such as LamAiR, SLED, IATA TERESA, ECHO, etc., he has gathered long-term experience within the fields of aircraft lifecycle cost-benefit modeling and assessment, technology assessment as well as systems analysis. He is a member of the AIAA society. 